\title{
Cardiac sequelae of Kawasaki disease among recurrent cases
}

\author{
Yosikazu Nakamura, Hiroshi Yanagawa, Toshiyuki Ojima, Tomisaku Kawasaki, \\ Hirohisa Kato
}

\begin{abstract}
Objective-This study was undertaken to clarify whether cardiac sequelae due to Kawasaki disease are more frequent among recurrent cases than initial onset cases.

Study design-A cross sectional study using data from nationwide surveys of Kawasaki disease in Japan was conducted. A total of 33976 patients reported were divided into two groups: initial onset cases (32 923 patients) and recurrent cases (1053 patients). Proportions of cardiac sequelae such as coronary aneurysms/dilatation, coronary stenosis/narrowing, myocardial infarction, and valvular lesions were compared between the two groups.

Results-The proportions of patients with the sequelae were significantly more common among recurrent cases. In men $25.5 \%$ of the recurrent cases had the sequelae in comparison with $14.9 \%$ for initial onset cases, and in women $16.1 \%$ of recurrent cases had the sequelae compared with $9.8 \%$ of initial onset cases. Giant coronary aneurysms were twice as likely in men in whom the disease was recurring than in initial onset cases, and 1.5 times more likely in women in whom the disease was recurring than in initial onset cases.

Conclusion-Cardiac sequelae of Kawasaki disease are more likely to appear on recurrent case patients.

(Arch Dis Child 1998;78:163-165)
\end{abstract}

Keywords: Kawasaki disease; cardiac sequelae

Y Nakamura

$\mathrm{H}$ Yanagawa

T Ojima

Japan Kawasaki

Disease Research

Centre, Tokyo

T Kawasaki

Department of

Paediatrics and Child

Health, Kurume

University School of

Medicine, Kurume,

Japan

H Kato

Correspondence and reprint requests to: Dr Yosikazu Nakamura, Department of Public Health, Jichi Medical School, 3311-1 Yakushiji, Minamikawachi, Tochigi 329-0498, Japan.

Accepted 26 September 1997 at $2.9 \% .^{2}$ However, it is still unclear whether the recurrent cases are more likely to have cardiac sequelae than patients experiencing the first attack of the disease.

To compare the proportions of cardiac sequelae among patients with initial onset Kawasaki disease and those with recurrent
Kawasaki disease, we analysed three recent nationwide surveys of the disease in Japan.

\section{Patients and methods}

The Japanese Research Committee of Kawasaki Disease conducted the 11th nationwide survey in January 1991, the 12th survey in January 1993, and the 13th survey in January 1995. ${ }^{2367}$ All patients visiting hospitals during a two year period from January 1989 to December 1990 were included in the 11 th survey. Target patients of the 12th and 13th surveys were those visiting during two year periods in 1991 and 1992 and in 1993 and 1994, respectively. The surveys were done by post, and the target hospitals were those with 100 or more beds and which had a paediatric department, and paediatric hospitals.

The questionnaires reported for each patient whether they had cardiac sequalae. The committee defined the cardiac sequelae as one of the following: occurring in a one month period from the onset of disease; coronary aneurysms including dilatation; coronary stenosis including narrowing, myocardial infarction, and valvular lesions. ${ }^{28}{ }^{9}$ In addition to this information regarding cardiac sequelae, detailed data were required in the last two surveys. If a patient had a sequela, its type (giant coronary aneurysms, coronary aneurysms/dilatation, coronary stenosis/ narrowing, myocardial infarction, and valvular lesions) was reported. It was noted also whether a patient had initial onset of the disease or recurrent onset. Information was based on the paediatrician's diagnosis.

According to the surveys, all patients were divided into two groups: those affected by the disease for the first time (initial onset cases) and those affected for the second time or more (recurrent cases). Firstly, we compared the proportions of patients with the cardiac sequelae between the two groups with age strata by sex, because the proportion depends on age. Secondly, the proportions of specific sequelae were observed using the data from the 12th and 13th surveys. Age adjusted proportions were obtained by direct methods with all patients' ages constructed as for a standard population. Fisher's exact tests were used to evaluate statistical significance, and a probability less than 0.05 was considered significant.

\section{Results}

Table 1 shows the number and proportion of patients with cardiac sequelae in the two groups by age and sex. The proportions among recurrent cases were significantly higher 
Table 1 The numbers of patients with Kawasaki disease and patients with cardiac sequelae due to the disease among the initial onset cases and recurrent cases, by age and sex, 1989-94, Japan

\begin{tabular}{|c|c|c|c|c|}
\hline \multirow[b]{2}{*}{ Age } & \multicolumn{2}{|c|}{ Initial onset case } & \multicolumn{2}{|c|}{ Recurrent case } \\
\hline & Patients & $\begin{array}{l}\text { With cardiac } \\
\text { sequelae (\%) }\end{array}$ & Patients & $\begin{array}{l}\text { With cardiac } \\
\text { sequelae (\%) }\end{array}$ \\
\hline \multicolumn{5}{|l|}{ Boys } \\
\hline$<6$ months & 2357 & $491(20.8)$ & 23 & $6(26.1)$ \\
\hline $6-11$ months & 3628 & $546(15.0)$ & 54 & $14(25.9)^{\star}$ \\
\hline $12-23$ months & 4902 & $614(12.5)$ & 139 & $32(23.0)^{\star \star}$ \\
\hline $2-4$ years & 6414 & $869(13.5)$ & 291 & $69(23.7)^{\star \star}$ \\
\hline $5-9$ years & 1722 & $296(17.2)$ & 127 & $39(30.7)^{\star \star}$ \\
\hline$\geqslant 10$ years & 108 & $27(25.0)$ & 7 & $4(57.1)^{\star \star}$ \\
\hline Unknown & 77 & $11(14.3)$ & 3 & 0 \\
\hline Total & 19208 & $2854(14.9)$ & 644 & $164(25.5)^{\star \star}$ \\
\hline \multicolumn{5}{|l|}{ Girls } \\
\hline$<6$ months & 1669 & $250(15.0)$ & 15 & $2(13.3)$ \\
\hline 6-11 months & 2319 & $228(9.8)$ & 24 & $4(16.7)$ \\
\hline $12-23$ months & 3401 & $314(9.2)$ & 65 & $11(16.9)^{\star}$ \\
\hline $2-4$ years & 4786 & $394(8.2)$ & 195 & $27(13.8)^{\star \star}$ \\
\hline 5-9 years & 1436 & $138(9.6)$ & 100 & $20(20.0)^{\star \star}$ \\
\hline$\geqslant 10$ years & 70 & $13(18.6)$ & 9 & $2(22.2)$ \\
\hline Unknown & 34 & $4(11.8)$ & 1 & 0 \\
\hline Total & 13715 & $1341(9.8)$ & 409 & $66(16.1)^{\star \star}$ \\
\hline
\end{tabular}

${ }^{\star} \mathrm{p}<0.05 ;{ }^{\star \star} \mathrm{p}<0.01$ (Fisher's exact test).

Table 2 Crude and age adjusted proportions (\%) of patients with specific cardiac sequelae due to Kawasaki disease among initial onset cases and recurrent cases, by sex, 1991-4, fapan

\begin{tabular}{|c|c|c|c|c|}
\hline & \multicolumn{2}{|l|}{ Crude } & \multicolumn{2}{|c|}{ Age adjusted ${ }^{\dagger}$} \\
\hline & Initial onset & Recurrent & Initial onset & Recurrent \\
\hline \multicolumn{5}{|l|}{ Boys } \\
\hline $\mathrm{All}^{\ddagger}$ & 14.7 & $25.2^{\star \star}$ & 14.7 & $21.9^{\star \star}$ \\
\hline Giant coronary aneurysms & 1.5 & $3.5^{\star \star}$ & 1.5 & $2.9^{\star}$ \\
\hline Coronary aneurysms/dilatation & 12.9 & $21.7^{\star \star}$ & 12.9 & 13.8 \\
\hline Coronary stenosis/narrowing & 0.2 & $1.2^{\star \star}$ & 0.2 & $1.3^{\star \star}$ \\
\hline Myocardial infarction & 0.2 & 0.0 & 0.2 & 0.0 \\
\hline Valvular lesions & 0.6 & 0.5 & 0.6 & 0.1 \\
\hline \multicolumn{5}{|l|}{ Girls } \\
\hline All & 9.9 & $16.9^{\star \star}$ & 9.8 & $14.7^{\star}$ \\
\hline Giant coronary aneurysms & 0.4 & 1.1 & 0.4 & 0.6 \\
\hline Coronary aneurysms/dilatation & 9.0 & $15.3^{\star \star}$ & 9.0 & $14.0^{\star \star}$ \\
\hline Coronary stenosis/narrowing & 0.1 & 0.0 & 0.1 & 0.0 \\
\hline Myocardial infarction & 0.1 & 0.0 & 0.1 & 0.0 \\
\hline Valvular lesions & 0.5 & 0.4 & 0.5 & 0.2 \\
\hline
\end{tabular}

† Patients whose age was unknown were excluded.

$\ddagger$ Because some patients had two or more kinds of sequelae, the percentages differ from the combined values.

${ }^{\star} \mathrm{p}<0.05 ;{ }^{\star \star} \mathrm{p}<0.01$ (Fisher's exact test).

Table 3 The numbers of patients with Kawasaki disease and patients with three specific cardiac sequelae due to the disease among the initial onset cases and recurrent cases, by age, males, 1991-4, fapan

\begin{tabular}{|c|c|c|c|c|}
\hline \multirow[b]{2}{*}{ Age } & \multicolumn{2}{|c|}{ Initial onset case } & \multicolumn{2}{|c|}{ Recurrent case } \\
\hline & Patients & $\begin{array}{l}\text { With cardiac } \\
\text { sequelae (\%) }\end{array}$ & Patients & $\begin{array}{l}\text { With cardiac sequelae } \\
(\%)\end{array}$ \\
\hline \multicolumn{5}{|c|}{ Giant coronary aneurysms } \\
\hline$<6$ months & 1598 & $39(2.4)$ & 5 & $0(0.0)$ \\
\hline $6-11$ months & 2504 & $25(1.0)$ & 27 & $1(3.7)$ \\
\hline $12-23$ months & 3263 & $26(0.8)$ & 87 & $2(2.3)$ \\
\hline $2-4$ years & 4290 & $68(1.6)$ & 199 & $6(3.0)$ \\
\hline $5-9$ years & 1164 & $30(2.6)$ & 76 & $4(5.3)$ \\
\hline$\geqslant 10$ years & 69 & $2(2.9)$ & 5 & $1(20.0)$ \\
\hline \multicolumn{5}{|c|}{ Coronary aneurysms/dilatation } \\
\hline$<6$ months & 1598 & $279(17.5)$ & 5 & $0(0.0)$ \\
\hline $6-11$ months & 2504 & $323(12.9)$ & 27 & $5(18.5)$ \\
\hline $12-23$ months & 3263 & $379(11.6)$ & 87 & $21(24.1)^{\star \star}$ \\
\hline $2-4$ years & 4290 & $500(11.7)$ & 199 & $42(21.1)^{\star \star}$ \\
\hline $5-9$ years & 1164 & $165(14.2)$ & 76 & $16(21.1)$ \\
\hline$\geqslant 10$ years & 69 & $15(21.7)$ & 5 & $3(60.0)$ \\
\hline \multicolumn{5}{|c|}{ Coronary stenosis/narrowing } \\
\hline$<6$ months & 1598 & $5(0.3)$ & 5 & $0(0.0)$ \\
\hline $6-11$ months & 2504 & $6(0.2)$ & 27 & $1(3.7)$ \\
\hline $12-23$ months & 3263 & $9(0.3)$ & 87 & $0(0.0)$ \\
\hline $2-4$ years & 4290 & $6(0.1)$ & 199 & $3(1.5)$ \\
\hline $5-9$ years & 1164 & $3(0.3)$ & 76 & $0(0.0)$ \\
\hline$\geqslant 10$ years & 69 & $0(0.0)$ & 5 & $1(20.0)$ \\
\hline
\end{tabular}

$\star \star \mathrm{p}<0.01$ (Fisher's exact test).
(25.5\% in boys and $16.1 \%$ in girls) than those among initial onset cases $(14.9 \%$ in boys and $9.8 \%$ in girls). This trend existed in each age stratum, except in the age unknown groups and in the youngest age group of girls.

Table 2 shows the proportions of specific sequelae in the two groups. Because myocardial infarction, valvular lesions, and coronary stenosis/narrowing among girls were rare, conclusive results were not obtained. On the other hand, giant coronary aneurysms, coronary aneurysms/dilatation, and coronary stenosis/ narrowing among boys were more likely to occur in recurrent Kawasaki disease. In particular, among boys, giant coronary aneurysms were twice more likely to occur in recurrent disease compared with initial onset disease.

Table 3 shows the proportion of three major specific cardiac sequelae: giant coronary aneurysms, coronary aneurysms/dilatation, and coronary stenosis/narrowing by age for boys. Of 399 recurrent cases between 1991 and 1994 in boys whose ages were known, 14 were reported to have giant coronary aneurysms. Although table 2 showed the age adjusted proportion of patients with aneurysms/ dilatation was similar in the initial onset and recurrent groups, the analysis by age presented in table 3 shows that the proportion of patients with aneurysms/dilation is significantly greater in recurrent disease among patients aged $<6$ months, 12 months, and 2-4 years.

\section{Discussion}

In this study we have shown that the cardiac sequelae are more likely to be observed among recurrent cases than among initial onset cases. The main pathological finding of the disease is systemic vasculitis. ${ }^{10-14}$ It is reasonable to assume that two attacks of vasculitis damage the vascular wall more than only one attack, and the proportion of patients with cardiac sequelae due to Kawasaki disease, which are results of the vasculitis, was higher than that of initial onset cases.

A few studies indicate that recurrence of Kawasaki disease is a risk factor for cardiac involvement. ${ }^{5}{ }^{15}$ In Japan, Asai has assessed the risk factor and used it to create a scoring system to evaluate the severity of the disease. ${ }^{15}$ In the United States, Mason et al showed that five out of 10 patients with recurrent Kawasaki disease had coronary artery abnormalities, and they stress a certain vulnerability to the effect of the disease. ${ }^{5}$ Our results are consistent with these previous findings.

Our data provide suggestions for management of the patients after healing of Kawasaki disease. If a person with a history of Kawasaki disease is reaffected, the risk of cardiac sequelae is so high that he or she should be treated more carefully to avoid the sequelae. Because early treatment is essential, a paediatrician, as well as the patient's parents, should suspect the disease if the patient has a history of it and is showing early symptoms of Kawasaki disease, such as fever lasting a few days. Guidance for early identification of the disease should be given to patients' parents. 
Among patients with recurring Kawasaki disease, giant coronary aneurysms, which are the most severe sequelae of the disease, are twice as common for boys and 1.5 times as commom for girls as among the initial onset cases after adjustment for age. It is interesting to note whether recurrent cases with giant coronary aneurysms also had coronary aneurysms at the first attack of the disease. In other words, the question is whether giant coronary aneurysms appear unexpectedly at recurrence on intact coronary arteries at the initial onset, or coronary aneurysms of small or medium size develop with the second attack. Unfortunately, in this study the first and second episodes of the disease have not been linked; we estimate that it will take another few years to link more than 100000 individual records. Therefore, we have no answer to the question. However, we will develop a method of linking the personal data in the nationwide surveys and answer the question. Although our data may be incomplete, we believe it is still important to show the current results.

Age adjusted proportions of coronary aneurysms/dilatation were similar among the initial onset case group (12.9\%) and the recurrent group $(13.8 \%)$ in boys as table 2 shows. On the other hand the proportions were higher among recurrent cases except for those $<6$ months in the age specific observation (table $3)$. Recurrent cases aged $<6$ months, which means that a baby has the disease twice within six months of his or her birth, are very rare, and the weight for this age group is large in the age adjustment analysis; therefore, the age adjusted proportions were similar. The current data tell us that coronary aneurysms/dilatation and giant aneurysms are more common among recurrent cases then among initial onset cases.

In epidemiological studies such as this, definitions of diseases, involvements, etc, merit discussion. A definition of the cardiac sequelae was given in the questionnaire for paediatricians to follow. As many as $96.2 \%$ of the patients reported were from hospitals where echocardiography was available in the 13th nationwide survey ${ }^{16}$; almost all of the sequelae, therefore, were detected using echocardiographic examinations. In Japan, the consensus among paediatricians is that a patient with Kawasaki disease should be examined using echocardiography to detect cardiac involvements. Specific sequelae, such as giant coronary aneurysms and valvular diseases, have been defined by the Kawasaki Disease Research Committee, ${ }^{17}$ and they have been accepted widely among Japanese paediatricians. A giant coronary aneurysm is defined as an aneurysm of which the diameter is $8 \mathrm{~mm}$ or more. Thus we believe that despite the large size of the nationwide surveys no problems with definitions exist in our study.

In conclusion, using Japanese nationwide survey data of Kawasaki disease we have indicated that the cardiac sequelae were more likely to appear among recurrent cases. Also, giant coronary aneurysms were twice as common in male recurrent patients and 1.5 times as common for female ones as for initial onset cases. This research was conducted as a project study of the Japanese
Kawasaki Disease Research Committee, which was financially Kawasaki Disease Research Committee, which was financially
supported by the Ministry of Health and Welfare of the Japanese supported by
government.

1 Kato $\mathrm{H}$, Sugimura $\mathrm{T}$, Akagi $\mathrm{T}$, et al. Long-term consequences of Kawasaki disease: a 10 to 21 year follow-up quences of Kawasaki disease: a 10 to 21 year follow
study of 594 patients. Circulation 1996;94:1379-85.

2 Yanagawa H, Nakamura Y, Yashiro M, et al. Update of the epidemiology of Kawasaki disease in Japan. $\mathcal{f}$ Epidemiol epidemiology of

3 Yanagawa H, Yashiro M, Nakamura Y, et al. Results of 12 nationwide epidemiological incidence surveys of Kawasaki disease in Japan. Arch Pediatr Adolesc Med 1995;149:77983.

4 Nakamura Y, Yanagawa H. A case-control study of recurrent Kawasaki disease using the database of the nationwide surveys in Japan. Eur F Pediatr 1996;155:303-7.

5 Mason WH, Takahashi M, Schneider T. Recurrence of Kawasaki disease in a large urban cohort in the United States. In: Takahashi M, Taubert K, eds. Proceedings of the Fourth International Symposium on Kawasaki Disease. Dallas: American Heart Association, 1993;21-6.

6 Yanagawa H, Yashiro M, Nakamura Y, et al. Epidemiologic pictures of Kawasaki disease in Japan: from the nationwide incidence survey in 1991 and 1992. Pediatrics 1995;95: inciden 9 .

7 Nakamura $\mathrm{Y}$, Yanagawa $\mathrm{H}$, Kato $\mathrm{H}$, et al. Mortality rates for patients with a history of Kawasaki disease in Japan. $\mathcal{F}$ Pedipatients with a history

8 Nakamura Y, Fujita Y, Nagai M, et al. Cardiac sequelae of Nakamura Y, Fujita Y, Nagai M, et al. Cardiac sequelae of
Kawasaki disease in Japan: statistical analysis. Pediatrics 1991;88:1144-7.

9 Hirose K, Nakamura Y, Yanagawa H. Cardiac sequelae of Kawasaki disease in Japan over 10 years. Acta Paediatr $\mathcal{Y p}_{p} n$ 1995;37:667-71.

10 Nonoyama S. Immunologic abnormalities and endothelial cell injury in Kawasaki disease. Acta Paediatr Fpn 1991;33: $752-5$.

11 Bacon PA. Systemic vasculitis syndrome. Curr Opin Rheumatol 1993;5:5-10.

12 Jennette JC, Falk RJ, Andrassy K, et al. Nomenclature of systemic vasculitides. Proposal of an international consensus conference. Arthritis Rheum 1994;37:187-92.

13 Peterson-Sweeney KL. Systemically induced vasculitis in children. AACN Clin Issues 1995; 6:657-69.

children. AACN Clin Issues 1995; 6:657-69.
4 Smith JG Jr. Vasculitis. J Dermatol 1995;22:812-22.

14 Smith JG Jr. Vasculitis. F Dermatol 1995;22:812-22. Kawasaki disease. Acta Paediatr fpn 1983;25:170-5.

16 Koyanagi H, Nakamura Y, Yashiro M, et al. Hospital facilities available to patients with Kawasaki disease: results of a national survey of Kawasaki disease in Japan. Acta Paediatr fpn 1996;38:562-6.

17 Kawasaki Disease Research Committee. Guidelines for treatment and management of cardiovascular sequelae in Kawasaki disease. Acta Paediatr Ұpn 1987;29:109-14. 